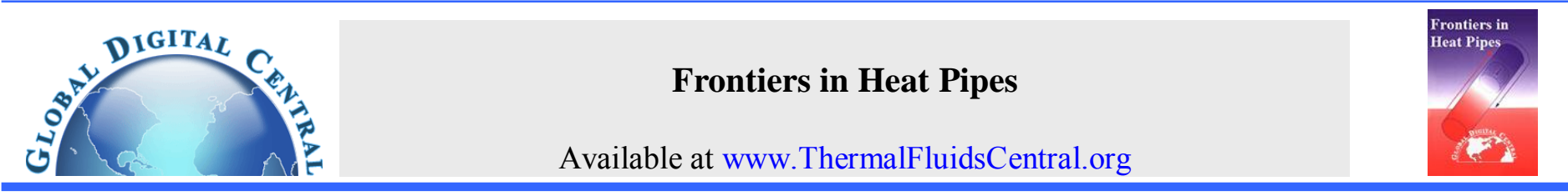

\title{
BOILING AND CONDENSATION HEAT TRANSFER COEFFICIENTS FOR A HEAT PIPE HEAT EXCHANGER
}

\author{
R. Laubscher, R.T. Dobson* \\ Department of Mechanical and Mechatronic Engineering, University of Stellenbosch, Stellenbosch \\ Private Bag X1, MATIELAND 7602, South Africa
}

\begin{abstract}
This paper reports on the experimental determination of the boiling and condensation heat transfer coefficients for the working fluid of a novel heat pipe heat exchanger at high operating temperatures. This technology is of importance in the high-temperature gas cooled nuclear power and process heat industries as it eliminates the probability of tritium finding its way into the product stream. The high temperature working fluid used to evaluate the heat pipe heat exchanger was Dowtherm-A, a special high temperature eutectic mixture of $26.5 \%$ diphenyl and $73.5 \%$ diphenyl oxide. A specially designed experimental heat pipe heat exchanger was built using a hot gas stream of up to $600{ }^{\circ} \mathrm{C}$ as the heating stream and cold water as the cooling stream. The basic features of the design are given. The experimental model is used as a proof of concept and to validate the theoretical heat transfer modeling analyses. Existing heat transfer coefficients correlations were considered; they include the Rohsenow, Stephan and Abdelsalam, Gorenflo, and Kutateladze correlations. None of these correlations gave satisfactory results and as such experimentally determined boiling and condensation correlations were determined and which gave reasonable results.
\end{abstract}

Keywords: Heat pipe heat exchanger, Dowtherm-A, heat transfer coefficients, boiling, condensation.

\section{INTRODUCTION}

Operating at fuel temperatures in excess of $950{ }^{\circ} \mathrm{C}$, as most very high temperature gas-cooled nuclear reactors are expected to do, the formation of tritium in the reactor and its occurrence in the coolant stream is of concern. At these high temperatures tritium $\left(\mathrm{H}^{3}\right)$ has a particularly high diffusion rate through steel (Jousse, 2007) and may conceivably find its way into the process stream and ultimately into a consumer product. It has been suggested that this concern might be addressed by including an additional heat transfer loop between the primary reactor coolant loop and the process heat steam loop. Such an additional heat transfer loop would require an additional heat exchanger, additional pipework and circulation pump and a high temperature and pressure gas or low pressure but high temperature liquid metal as the working fluid. Because of the additional heat exchanger there will, needs be, also be an additional degradation of the available process stream temperature. A novel natural circulation twophase thermosyphon-type heat pipe heat exchanger (HPHE) has been suggested by Dobson and Laubscher (2013). A concept drawing of such a heat transfer device is given in Fig. 1.

The concept HPHE shown in Fig. 1 consists essentially of a working fluid container more-or-less half charged with a liquid in thermal equilibrium with its vapour; and by a judicious choice of working fluid, at a relatively low pressure, say 0.5 to $1.5 \mathrm{kPa}$. The high pressure hot fluid stream is channeled through the evaporator section, whilst the stream being heated is channeled through high-pressurewithstanding tubes positioned in the vapour of the condenser section. The working fluid boils in the evaporator and condenses as a film on the colder tubes, collects and forms droplets which, under the influence of gravity, fall back into the liquid pool. In this way the latent heat of

* Corresponding author email: rtd@sun.ac.za vaporization is transferred with essentially no temperature drop. [This heat transfer is thus reminiscent of a closed two-phase thermosyphontype heat pipe.] The need for an extra heat exchanger, circulating pump and pipe work and high pressure working fluid container is thus also avoided.

Note that in Fig. 1 both the hot stream and the cold stream are shown as single tubes passing through the container. In an actual practical case there will be a large number of tubes and these tubes will not pass straight though the container. It is more likely that the hot and cold stream fluids will pass through a two-tube-pass heat exchange single shell (for the container) as in conventional tubular heat exchangers technology. The actual design would have to take careful cognisance of differential thermal expansion stresses, strains and deformation. The reason the concept has only two single tubes is for

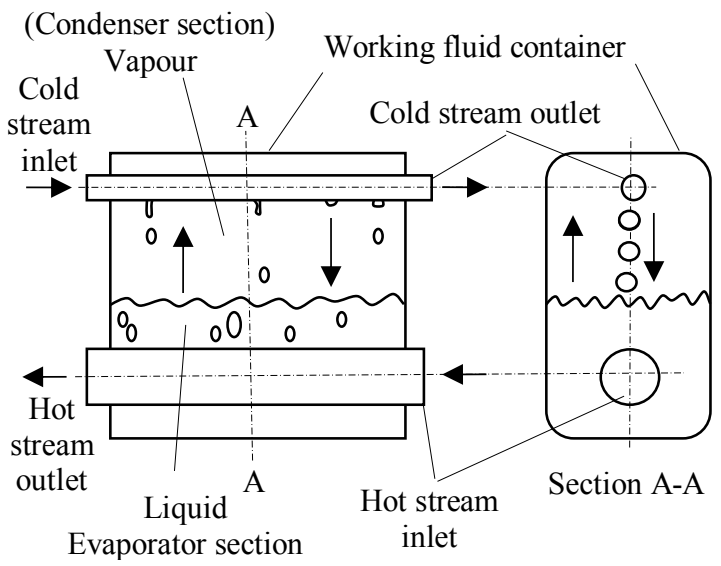

Fig. 1 Concept drawing of a novel heat pipe heat exchanger (HPHE). 
ease of experimental data capture and analysis, as single tube heating ("pool boiling") and condensing ("film-wise") geometries are well documented in the published literature.

Although the indicated HPHE working fluid for a $950{ }^{\circ} \mathrm{C}$ primary heating stream is sodium, it was deemed expedient from a safety and practical point of view to first conduct tests at an intermediate temperature. The highest non-toxic, non-flammable and commercially available working fluid for this purpose is Dowtherm-A. It is a eutectic mixture of $20.5 \%$ biphenyl and $70.5 \%$ diphenyl oxide, and is supplied by the Dow Chemical Company (1997). Its properties are given in Table 1 where it is seen that its boiling point at one atmosphere is $257.1^{\circ} \mathrm{C}$; and it is stored, shipped and suplied in conventional 210 litre (55 US gallons) standard steel drums (or so-called "barrels"). Unfortunately however the long-term stability of Dowtherm-A has as yet not been fully established and demonstrated.

A theoretical heat transfer model for a HPHE was developed (Laubscher, 2013), but the model then needed to be validated. To do this an experimental apparatus was designed, constructed and tested. To experimentally validate the theoretical model the boiling and condensation heat transfer coefficients for Dowtherm-A were needed. It thus follows that the objectives of this paper may be summarised as follows:

- Document and evaluate the existing and available boiling and condensation heat transfer coefficient correlations that could be applicable to Dowtherm-A.

- Observe the general flow behavior of the working fluid in the container by means of direct visual observation through windows in the sides of the experimental test apparatus. Also to check whether the vapour-liquid flow occurs in more-orless vertical planes along the length of the tubes; as this was assumed to be the case in the theoretical model.

- Evaluate the applicability of the existing correlations for Dowtherm-A as working fluid, and if needs be generate a new and better correlation.

To meet these objectives a literature study was undertaken in section 2 in order to identify appropriate boiling and condensation correlations for inclusion into the theoretical model. The experimental work that was undertaken, in which a Dowtherm-A charged, HPHE was built and tested is described in section 3. Based on the experimental test results two new correlations were determined in section 4 ; one for the boiling and the other for the condensation heat transfer coefficients. An evaluation of the accuracy and applicability of the experimental and theoretical correlations was done and briefly discussed and conclusions are drawn in section 5 .

Table 1 Thermal properties of Dowtherm-A (Dow Chemical Company, 1997).

\begin{tabular}{|l|c|c|}
\hline Property & value & units \\
\hline Freezing point & 12 & ${ }^{\circ} \mathrm{C}$ \\
\hline Boiling point at 1 atmosphere & 257.1 & ${ }^{\circ} \mathrm{C}$ \\
\hline Flash point & 113 & ${ }^{\circ} \mathrm{C}$ \\
\hline Fire point & 118 & ${ }^{\circ} \mathrm{C}$ \\
\hline Auto-ignition point & 599 & ${ }^{\circ} \mathrm{C}$ \\
\hline Density at $20{ }^{\circ} \mathrm{C}$ & 1056 & $\mathrm{~kg} / \mathrm{m}^{3}$ \\
\hline Critical temperature & 497 & ${ }^{\circ} \mathrm{C}$ \\
\hline Critical pressure & 313.4 & $\mathrm{kPa}$ \\
\hline Heat of combustion & 30053 & $\mathrm{~kJ} / \mathrm{kg}$ \\
\hline Latent heat at $100{ }^{\circ} \mathrm{C}$ & 345 & $\mathrm{~kJ} / \mathrm{kg}$ \\
\hline Dynamic viscosity at $25{ }^{\circ} \mathrm{C}$ & 3.71 & $\mathrm{mPas}$ \\
\hline Thermal conductivity of vapour at $25^{\circ} \mathrm{C}$ & 0.0081 & $\mathrm{~W} / \mathrm{m}{ }^{\circ} \mathrm{C}$ \\
\hline Thermal conductivity of liquid at $25^{\circ} \mathrm{C}$ & 0.1379 & $\mathrm{~W} / \mathrm{m}{ }^{\circ} \mathrm{C}$ \\
\hline Saturated temperature at $50 \mathrm{kPa}$ & 226.67 & ${ }^{\circ} \mathrm{C}$ \\
\hline
\end{tabular}

\section{LITERATURE STUDY}

When evaluating the thermal characteristics of a two-phase closed thermosyphon-type heat pipe it is important to consider the heat transfer coefficients between the internal working fluid and the wall surface in both the evaporator and the condenser sections (Pioro,1998), where the heat transfer coefficient is defined as

$$
h=\frac{\dot{Q}}{A\left(T_{\text {surface }}-T_{\text {working fluid }}\right)}
$$

\subsection{Boiling Heat Transfer Coefficient}

For boiling, the heat transfer coefficient depends on the boiling regime, of which there are four: natural convection, nucleate, transition and film boiling. Of the four, nucleate boiling is the most desirable boiling regime in practice because high heat transfer rates can be achieved in this regime and also with a relatively small temperature difference between the heated surface and liquid (Cengel 2006). For nucleate boiling, the heat flux is the dominant factor influencing the heat transfer coefficient. The heat transfer rate is also influenced by the physical properties of the working fluid, which may even vary along the axial length of the heat exchanger. In general, nucleate boiling heat transfer coefficient correlations contain a wall heat flux, a temperature term to capture the fluid pressure and density and a fluid property dependent factor, such as the fluid Prandtl number, to capture the effect of thermal conductivity, surface tension and heat capacity (Pioro et al. 2004). Thome (2006) stated that experimental results for heat flux $\dot{q}$ and wall superheat $\Delta T$ typically fit to an exponential equation of one of the following forms, $\dot{q} \propto \Delta T^{\mathrm{n}}, h_{\mathrm{b}} \propto \Delta T^{\mathrm{n}}$ or $h_{\mathrm{b}} \propto \dot{q}^{\mathrm{n}}$, where $\mathrm{n}$ equals 3,2 or 0.7 , respectively.

The Rohsenow's (1962) boiling heat transfer correlation is the most widely used and can be used for any geometry, since it was found that the rate of heat transfer during nucleate boiling is essentially independent of the geometry and orientation of the heater surface; rather, it is more dependent on the bubble pumping. The Rohsenow correlation is

$\frac{c_{p} \Delta T_{\mathrm{b}}}{h_{\mathrm{fg}}}=\mathrm{C}_{\mathrm{sf}}\left[\frac{\dot{q}}{\mu_{\mathrm{l}} h_{\mathrm{fg}}} \sqrt{\frac{\sigma}{\mathrm{g}\left(\rho_{\mathrm{l}}-\rho_{\mathrm{v}}\right)}}\right]^{0.33}\left(\frac{\mathrm{c}_{p} \mu_{l}}{k_{\mathrm{l}}}\right)^{\mathrm{n}}$

The results obtained using the Rohsenow correlation can be out by about $100 \%$ for the heat transfer rate, given a temperature difference between the saturated liquid and the heated surface (or the excess temperature); and given the heat transfer rate may be out by about $30 \%$ for the excess temperature. For Dowtherm A, the constant $\mathrm{C}_{\mathrm{sf}}$ is 0.00695 and $n$ is 1.72 (Jouhara, 2005).

Stephan and Abdelsalam (1980) formulated a correlation containing four groups of variables using regression techniques for water, refrigerants, organics and cryogens as

$$
\begin{aligned}
\frac{h_{\mathrm{b}} d_{\mathrm{bub}}}{k_{\mathrm{l}}}=0.0546\left[\left(\frac{\rho_{\mathrm{v}}}{\rho_{\mathrm{l}}}\right)^{0.5}\left(\frac{\dot{q} d_{\mathrm{bub}}}{k_{\mathrm{l}} T_{\mathrm{sat}}}\right)\right]^{0.67} & {\left[\frac{h_{\mathrm{fg}} d_{\mathrm{bub}}{ }^{2}}{\mathrm{a}_{\mathrm{L}}^{2}}\right]^{0.248} } \\
& {\left[\frac{\rho_{\mathrm{l}}-\rho_{\mathrm{g}}}{\rho_{\mathrm{l}}}\right]^{-4.33} }
\end{aligned}
$$

where $d_{\text {bub }}$ is the bubble departure diameter, and is given by

$d_{\mathrm{bub}}=0.0146(\beta)\left[\frac{2 \sigma}{\mathrm{g}\left(\rho_{1}-\rho_{\mathrm{g}}\right)}\right]^{0.5}$

where $\beta$ is the contact angle that may be assigned a fixed value of $35^{\circ}$, irrespective of the fluid, and $a_{\mathrm{L}}$ is an an experimentally determined parameter. This correlation is for organic fluids and it could be expected that it would also generate accurate results for Dowtherm-A.

Gorenflo (1993) proposed a fluid-specific correlation and included the effect of surface roughness and reduced pressures and contains a 
working fluid specific and a reference heat transfer coefficient $\alpha_{0}$, and is given by

$h_{\mathrm{b}}=\alpha_{\mathrm{o}} F_{\mathrm{PF}}\left(\frac{\dot{q}}{\dot{q}_{\mathrm{o}}}\right)^{\mathrm{nf}}\left(\frac{R_{\mathrm{p}}}{r_{\mathrm{po}}}\right)^{0.133}$

where the pressure correction factor $\mathrm{F}_{\mathrm{PF}}$ is given by

$$
F_{\mathrm{PF}}=1.2 \mathrm{P}_{\mathrm{r}}^{0.27}+2.5 \mathrm{P}_{\mathrm{r}}+\frac{\mathrm{P}_{\mathrm{r}}}{1-\mathrm{P}_{\mathrm{r}}}
$$

and

$$
\mathrm{nf}=0.9-0.3 \mathrm{P}_{\mathrm{r}}^{0.3}
$$

where $R_{\mathrm{p}}$ is the surface roughness and is set at $0.4 \mu \mathrm{m}$ when unknown. This correlation is applicable for a reduced pressure range from about 0.0005 to 0.95 , and is known to be applicable over a wide range of heat fluxes and pressures and according to Thome (2006) is also very reliable.

The Kutateladze et al. $(1961,1966)$ correlation is applicable to a wide range of conditions (fluid type, heater geometry and surface roughness) and is given by

$\frac{h_{\mathrm{b}} l_{*}}{k_{\mathrm{l}}}=0.44\left(\frac{1 \times 10^{-4} \dot{q} P}{\mathrm{~g} h_{\mathrm{fg}} \rho_{\mathrm{v}} \mu_{\mathrm{l}}} \frac{\rho_{\mathrm{l}}}{\left(\rho_{\mathrm{l}}-\rho_{\mathrm{v}}\right)}\right)^{0.7} \operatorname{Pr}^{0.35}$

\subsection{Condensation Heat Transfer Coefficient}

The laminar film condensation heat transfer coefficient is determined theoretically by using a force and energy balance over a liquid element within the condensate film flowing around the condenser tube, rather than by generalisations of experimental data (Mills, 1995). It is dependent on the thermal conductivity of the working fluid and the thickness of the condensate film on the condenser tube and is given by

$h_{\mathrm{c}}=\frac{k_{\mathrm{l}}}{\delta}$

The film thickness $\delta$ is a function of the Reynolds number, liquid and vapour densities, gravity and angle of location on the condenser wall $\phi$ and is given by

$\delta=\left(\frac{3}{4} \frac{\rho_{1} v_{1}^{2}}{\left(\rho_{1}-\rho_{\mathrm{v}}\right) \mathrm{ge}} \frac{\mathrm{Re}}{\sin \phi}\right)^{1 / 3}$

where the Reynolds number is given as

$\mathrm{Re}=2.5872 \frac{4}{3} \frac{2 k_{\mathrm{l}}\left(T_{\mathrm{sat}}-T_{\mathrm{S}}\right) d}{\mu_{1} h_{\mathrm{fg}}}\left[\frac{4}{3} \frac{\left(\rho_{l}-\rho_{\mathrm{v}}\right) \mathrm{g}}{\rho_{\mathrm{l}} v_{\mathrm{l}}^{2}}\right]^{\frac{1}{3}}$

Integrating around the periphery of the condenser tube, the average heat transfer coefficient for laminar film condensation of a horizontal tube can be derived, as

$\bar{h}_{\mathrm{c}}=0.728 \frac{\left(\rho_{\mathrm{l}}-\rho_{\mathrm{v}}\right) \mathrm{g} h_{\mathrm{fg}} k_{1}^{3}}{\mathrm{~N} v_{1} D\left(T_{\mathrm{sat}}-T_{\mathrm{s}}\right)}$

\section{EXPERIMENTAL WORK}

An experimental heat pipe heat exchanger was designed, built and installed in the laboratory, as shown in Figure 2. As well as allowing for the experimental determination of the heat transfer rates and the boiling and condensation heat transfer coefficients, it also has windows in the front and backside thus allowing visual observation of internal working fluid behaviour. A hot stream flows through the evaporator pipe and heats the liquid and boiling occurs. The so-formed vapour fills the vapour section above the liquid. The vapour then condenses on the condenser tubes and heat is in turn then transferred from the condenser wall, through the tube wall and into the cold stream liquid.

The HPHE consists of a container for the working fluid, a 101.6 $\mathrm{mm}$ diameter evaporator tube and a $21.3 \mathrm{~mm}$ diameter condenser tube, all of 316L stainless steel, and two large glass windows. Also shown in Fig. 2 is the pipework, flow control valves, pressure relief valve, constant head water supply tank, working fluid sump and vacuum pump. (Not show is the continuous combustion chamber hot gas supply and the mild steel support structures.) K-type thermocouples were used for all the temperature measurements. The thermocouple junctions were positioned at four vertical-plane locations along the axial length of the pipes, $0.058,0.248,0.428$ and $0.618 \mathrm{~m}$ from the hot stream inlet side. For each vertical plane three temperatures measurements were taken around the periphery of the heat exchange pipes, in the liquid next to and just above the evaporator pipe, and two above each other in the vapour space; giving a total of 44. Four thermocouples were used to measure the inlet and outlet temperatures of the heating gas and cooling water. The room temperature was also measured. Mass flow rate of the combustion gases was determined using a bell-mouth located at the gasburner inlet to which was added the liquefied petroleum gas (LPG) fuel, as measured using an orifice-plate type flow meter. The mass flow rate of the cold water stream from the constant heat tank was determined using a measuring-cylinder and stop-watch.

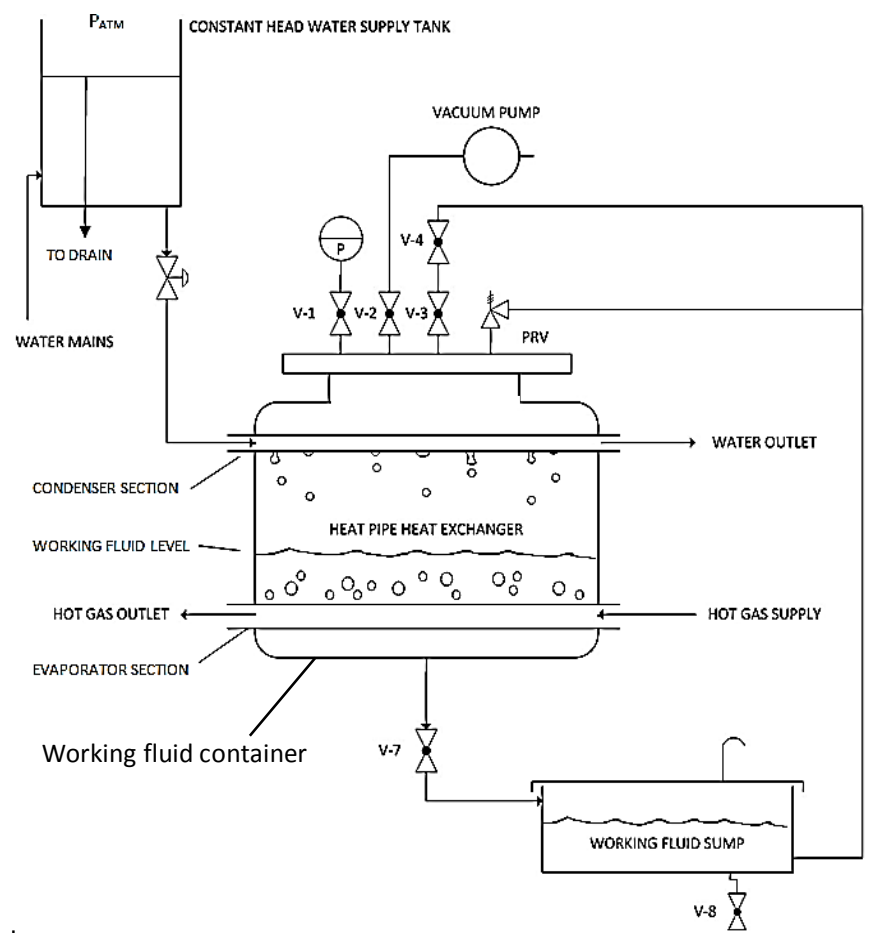

Fig. 2 Schematic layout of experimental setup. The dimensions of the working fluid container are (excluding the flanged instrumentation and observation platforms) $596 \mathrm{~mm}$ high, $671 \mathrm{~mm}$ wide and $516 \mathrm{~mm}$ deep. The hot gas tube diameter is $101.6 \mathrm{~mm}$, whilst that of the cold water pipe in the vapour space is $21.8 \mathrm{~mm}$.

\section{RESULTS AND ANALYSIS}

During experimentation visual inspection was done on the boiling and condensation processes by observing the evaporator and condenser through a glass window, which was incorporated into the experimental design. Figure 3 shows a photograph of the HPHE evaporator section whilst boiling. When observing the evaporator during operation the following is noted: the working fluid flows mainly radially away from the evaporator surface and the boiling frequency (bubble formation and 
separation) is observed to be almost constant. Figure 4 shows a photograph of the condenser section during operation. When observing the condensation process the following is noted: all along the length of the condenser droplets forms at the bottom of the condenser tube and when the droplet is large enough it detaches itself from the tube surface and falls into the working fluid pool. It is also noted that there is no droplet formation on the remaining periphery of the condenser tube. The more detailed boiling and condensation experimental procedure will be processed and discussed next.

\subsection{Boiling Heat Transfer Coefficient}

The experimental boiling heat transfer coefficient was determined by dividing the experimentally determined evaporator wall heat flux $\dot{\mathrm{q}}_{\text {in }}$ with the difference between the experimentally measured difference between the saturated working fluid temperature and the average wall surface temperature $\left(\bar{T}_{\text {s evap }}-\bar{T}_{1}\right)$ as

$h_{\mathrm{b}}=\frac{\dot{\mathrm{q}}_{\text {in }}}{\left(\bar{T}_{\mathrm{sevap}}-\bar{T}_{\mathrm{l}}\right)}$

where

$\dot{q}_{\text {in }}=\frac{\dot{Q}_{\text {in }}}{2 \pi r_{\text {evap o }} L_{\text {evap }}}$

and

$\dot{Q}_{\text {in }}=\dot{m}_{\text {hot }} c_{p \text { hot }}\left(T_{\text {hot inlet }}-T_{\text {hot outlet }}\right)$

where $\bar{T}_{\text {s evap }}$ is the average of all the evaporator surface thermocouple temperature readings and $\bar{T}_{1}$ is the average liquid pool temperature in the heat exchanger.

Figure 5 shows the experimentally determined boiling heat transfer coefficients as a function of the wall heat flux; also shown are the four correlations mentioned in the literature study. It is seen that the average experimentally determined heat transfer coefficient is about 5000 $\pm 1000 \mathrm{~W} / \mathrm{m}^{2} \mathrm{~K}$ and that it is relatively insensitive to the heat flux. All the correlations gleaned from the literature are all seen to under-predict the experimental values by roughly $3000 \mathrm{~W} / \mathrm{m}^{2} \mathrm{~K}$ or about $70 \%$. As this is a relatively large discrepancy an experimentally determined heat transfer coefficient correlation of form $\mathrm{h}_{\mathrm{b}}=\mathrm{C} \dot{\mathrm{q}}_{\mathrm{evap}}^{\mathrm{m}} \mathrm{P}_{\mathrm{r}}^{\mathrm{n}} \mathrm{T}_{\mathrm{sat}}^{\mathrm{z}}$ was considered. The liquid-surface temperature difference is captured by $\dot{\mathrm{q}}_{\text {evap }}^{\mathrm{m}}$, the ability of the heat to diffusion through the liquid by the $\operatorname{Pr}^{\mathrm{n}}$, and the fluid properties by $\mathrm{T}_{\text {sat }}^{\mathrm{z}}$. The constants $\mathrm{C}, \mathrm{m}, \mathrm{n}$ and $\mathrm{z}$ were determined using multivariable linear regression to give an experimentally determined boiling heat transfer coefficients of

$h_{\mathrm{b}}=0.485 \times 10^{-4} \dot{q}_{\text {evap }}^{-0.07675} \operatorname{Pr}^{0.686} T_{\text {sat }}^{0.9287}$

Fig. 6 shows that equation 16 predicts the boiling heat transfer coefficients to within $\pm 10 \%$ of the experimentally determined boiling heat transfer coefficients.

\subsection{Condensation Heat Transfer Coefficient}

The experimental condensation heat transfer coefficient was determined using

$h_{\mathrm{c}}=\frac{\dot{q}_{\text {out }}}{\left(\bar{T}_{\mathrm{v}}-\bar{T}_{\mathrm{s}, \text { cond }}\right)}$

where

$\dot{q}_{\text {out }}=\frac{\dot{Q}_{\text {out }}}{2 \pi r_{\text {co }} L_{\text {cond }}}$ where

$\dot{Q}_{\text {out }}=\dot{m}_{\text {cold }} c_{\text {p cold }}\left(T_{\text {cold outlet }}-T_{\text {cold inlet }}\right)$

$\bar{T}_{\mathrm{v}}$ is the average vapour temperature in the heat exchanger and $\overline{\mathrm{T}}_{\mathrm{s} \text { cond }}$ is the average condenser tube surface temperature. In figure 7 the condensation heat transfer coefficient as calculated by equation 18 is seen to be more or less constant for all the experimental value from 0 to $5000 \mathrm{~W} / \mathrm{m}^{2} \mathrm{~K}$. Assuming a correlation of the form $h_{\text {cond }}=\mathrm{CRe}^{\mathrm{m}} T_{\text {sat }}^{\mathrm{n}}$ the constants $\mathrm{C}, \mathrm{m}$ and $\mathrm{n}$ were also determined using multivariable linear regression to obtain a correlation with $R^{2}=0.927$ of the form

$h_{\mathrm{c}}=0.01074 \mathrm{Re}^{-2.667} T_{\mathrm{sat}}^{4.3}$

Figure 8 shows that equation 18 better predicts the condensation heat transfer rate than does the so-called Nusselt theory as given by equation 12 , but with a relatively wide scatter band of $\pm 70 \%$.

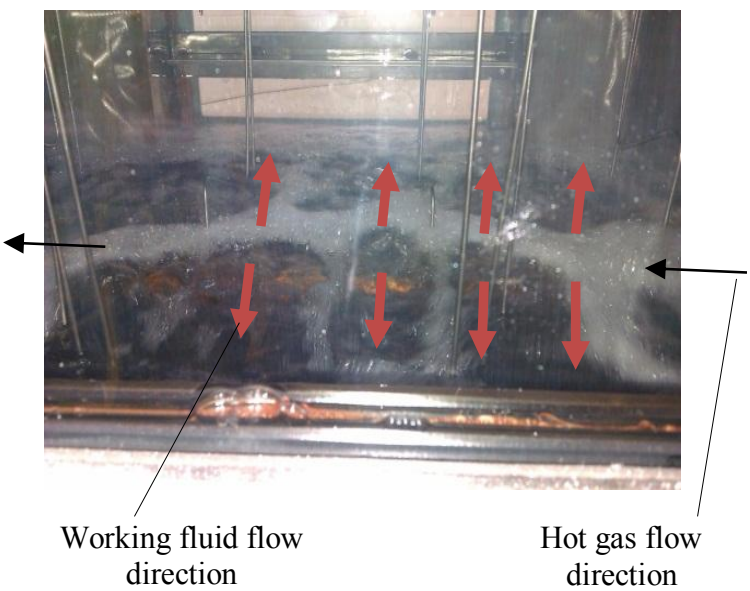

Fig. 3 Photograph of evaporator tube.

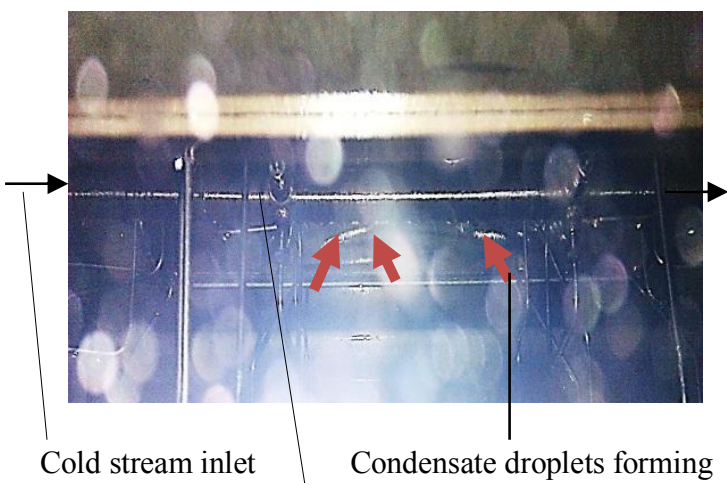

Condenser tube

Fig. 4 Photograph of condensation process.

\section{CONCLUSIONS}

- The boiling heat transfer coefficient of the heat pipe heat exchanger using Dowtherm A was experimentally determined and it was found that the correlations ascribed to Rohsenow, Gorenflo, StephanAdelsalam, and Kutateladze and as given by equations 2, 3, 4 and 5, respectively were all some $70 \%$ too low. The experimentally determined correlation for boiling heat transfer coefficient as given by equation 16, however, captured the experimental values to within $\pm 10 \%$. 
- The theoretically determined condensation heat transfer coefficient assuming film-wise condensation theory and as was calculated using equation 12 did not really correlate with the experimentally determined heat transfer coefficient values. As shown in Fig. 7, for experimentally determined values ranging from 1000 to 5000 $\mathrm{W} / \mathrm{m}^{2} \mathrm{~K}$, the theoretical value remained more-or-less constant at $1400 \mathrm{~W} / \mathrm{m}^{2} \mathrm{~K}$. From this it is concluded that traditional film-wise condensation theory should not be automatically be assumed to apply in the case of the condensation process as exhibited in the heat pipe heat exchanger.

- The experimentally determined condensation heat transfer coefficient correlation as given by equation 20 did indeed capture the average experimental values as seen in figure 8 but then only to within $70 \%$ of the experimental values.

- The large scatter of the experimental condensation heat transfer coefficient results as exhibited in Fig. 8 can be ascribed to the following affect: as the droplets form at the bottom of the condenser tube the film thickness increases and therefore the condensation heat transfer coefficient value drops. When the droplet detaches itself from the condenser surface the film thickness suddenly decreases and the condensation heat transfer coefficient value therefore rapidly

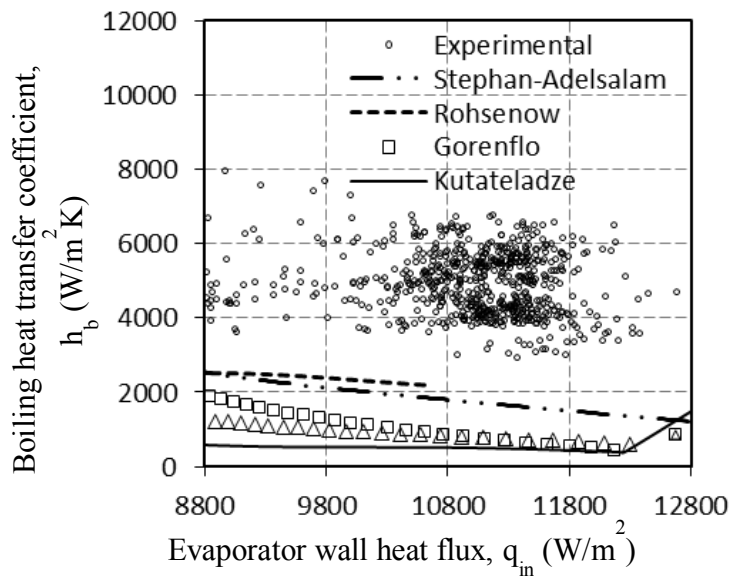

Fig. 5 Experimental and sundry boiling heat transfer coefficient correlations as a function of the evaporator wall heat flux.

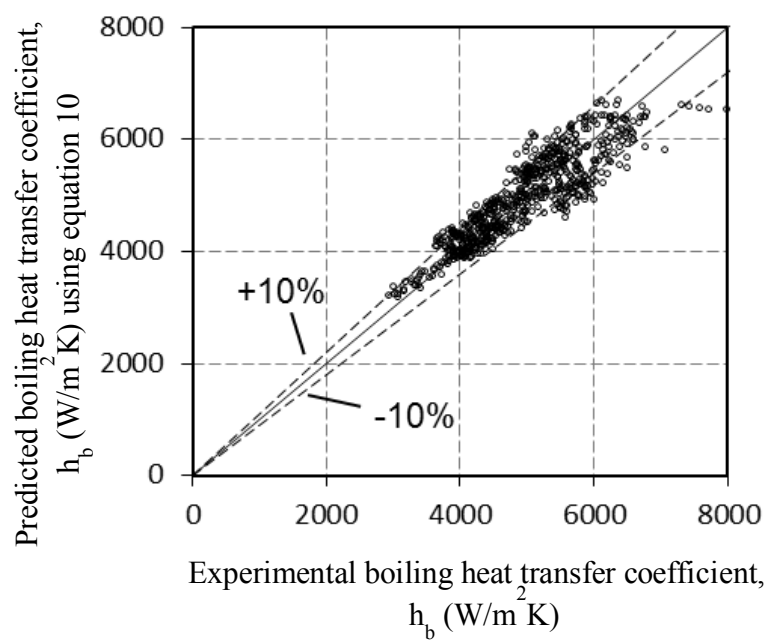

Fig. 6 Predicted boiling heat transfer coefficient (using equation 16) as a function the experimentally determined heat transfer coefficient. increases. Also liquid tends to collect at the ends of the thermocouple probes measuring the vapour temperature.

- A large amount of carry-over of liquid out of the liquid pool (as the vapour escapes out of the liquid pool) was not noticed. However, as intimated in the objectives in the introduction, the does indeed tend to flow as vapour upwards and liquid downwards in more-or-less vertical planes along the length of the tubes with apparently a minimum of flow parallel to the direction of the heating and cooling tubes. The assumption uniform upwards and downwards flow in formulating the theoretical model (Dobson and Laubscher, 2013; Laubscher, 2013) was thereby indeed validated.

\section{NOMENCLATURE}

$\begin{array}{ll}A & \text { Area, } \mathrm{m}^{2} \\ a & \text { Dimensional experimental variable } \\ c_{\mathrm{p}} & \text { Specific heat, } \mathrm{J} / \mathrm{kg} \mathrm{K} \\ \mathrm{C}_{\mathrm{sf}} & \text { Rohsenow constant } \\ D & \text { Diamter, } \mathrm{m} \\ \mathrm{D} & \text { Diamter, } \mathrm{m}\end{array}$

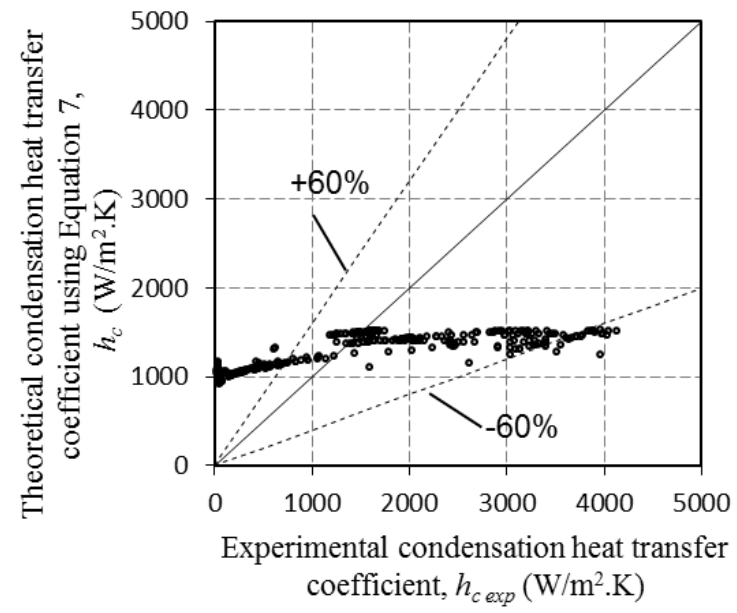

Fig. 7 Theoretical condensation heat transfer coefficient equation using Nusselt theory as a function of the experimental heat transfer coefficient results.

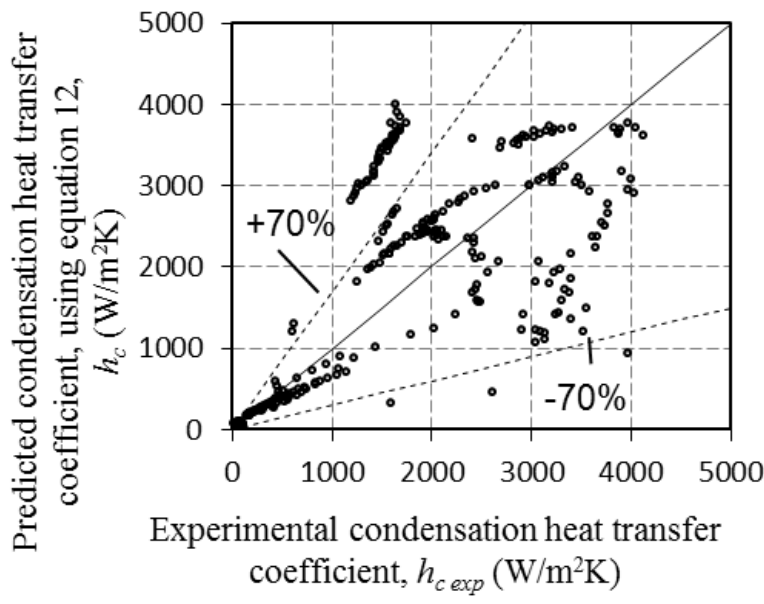

Fig. 8 Correlated (equation 19) condensation heat transfer coefficient equation as a function of the actual experimental heat transfer coefficient results. 


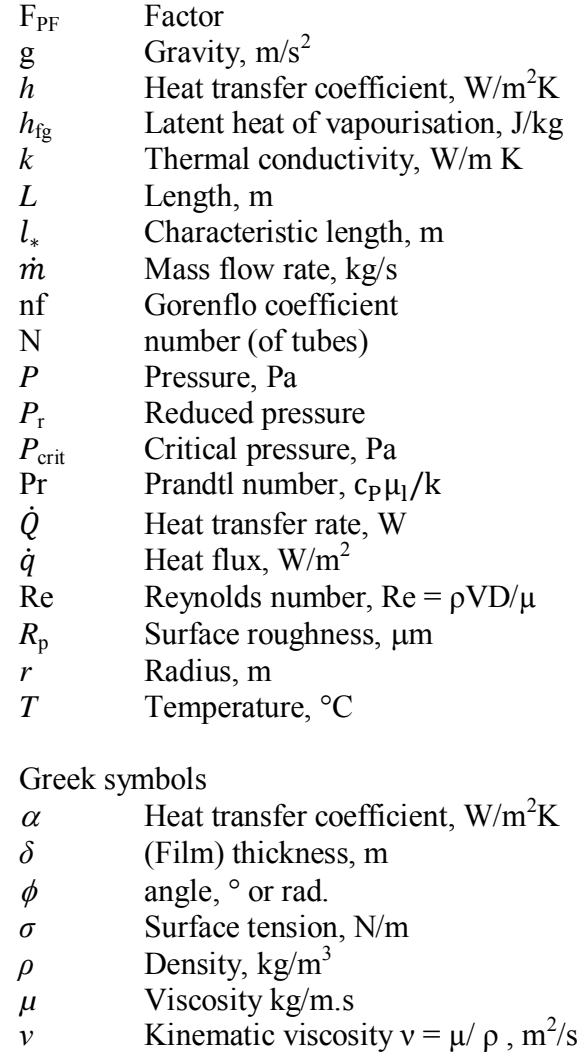

$\begin{array}{ll}\begin{array}{ll}\text { Subscripts } \\ \text { avg } \\ \text { b }\end{array} & \text { average } \\ \text { C } & \text { boiling } \\ \text { c } & \text { constant } \\ \text { cold } & \text { condensing } \\ \text { cond } & \text { Cold stream } \\ \text { evap } & \text { Condenser } \\ \text { hot } & \text { Evaporator } \\ \text { in } & \text { Hot stream } \\ \text { inlet } & \text { Into section } \\ \text { int } & \text { Inlet to HPHE } \\ \text { l } & \text { Internal } \\ \text { o } & \text { Liquid } \\ \text { out } & \text { Outside } \\ \text { outlet } & \text { Out of section } \\ \text { s } & \text { Out of HPHE } \\ \text { sat } & \text { Surface } \\ \text { v } & \text { Saturation } \\ \end{array}$

\section{REFERENCES}

Cengel, Y., 2006, Heat and Mass Transfer, McGraw Hill, New York.

Dobson, R.T. and Laubscher, R., 2013, "Heat Pipe Heat Exchanger for High Temperature Nuclear Reactor Technology," Proceedings of the 11th International Heat Pipe Symposium (11th IHPS), June 9-12, Beijing, China.

Dow Chemical Company, 1997, Dowtherm A Heat Transfer Fluid:

Product technical data. [Online] Available at:

http://msdssearch.dow.com/PublishedLiteratureDOWCOM/dh 0030/09

01b803800303cd.pdf?filepath $=/$ heattrans/pdfs/noreg/176-

01337.pdf\&fromPage $=$ GetDoc

Gorenflo, D., 1993, Pool Boiling, VDI-Heat Atlas, Dusseldorf, Germany.

Jouhara, H., 2009, “An Experimental Study of Wickless Miniature Heat Pipes Operating in the Temperature Range $200{ }^{\circ} \mathrm{C}$ to $450{ }^{\circ} \mathrm{C}$," Heat Transfer Engineering, 30(13), 1041-1048. http://dx.doi.org/10.1080/01457630902921113

Jousse, A., 2007, Tritium Transport in Very High Temperature Reactors for Hydrogen Production, Report Number UCBTH-07-005, University of California, 31 August.

Kutateladze, S.S and Borsnansky, V.M., 1966, "A Concise Encyclopaedia of Heat Transfer", Pergamon Press, New York.

Kutateladze, S.S, 1961, "Boiling Heat Transfer", International Journal of Heat and Mass Transfer, July, 31-45. http://dx.doi.org/10.1016/0017-9310(61)90059-X

Laubscher, R. and Dobson, RT., 2013, "Theoretical and Experimental Modeling of a Novel Heat Pipe Heat Exchanger for High Temperature Nuclear Reactors Technology," Applied Thermal Engineering, In print.

Mills, A.F., Heat Transfer, Prentice Hall, New Jersey, 1995.

Mostinskii, I.L., 1963, "Application of the Rule of Corresponding States for Calculation of Heat Transfer and Critical Heat Flux," Teploenergetika, 4, 66 .

Pioro, I.L., 1998, "Experimental Evaluation of Constants for the Rohsenow Pool Boiling Correlation," International Journal of Heat and Mass Transfer, 29, January, 2003-2013. http://dx.doi.org/10.1016/S0017-9310(98)00294-4

Pioro, I.L., Rohsenow, W. \& Doerffer, SS., "Nucleate pool-boiling heat transfer II: assessment of prediction methods," International Journal of Heat and Mass Transfer, 23, August 2004, pp. 5045-5057, 2004.

Rohsenow, W., "A Method of Correlating Heat Trasnfer Data for Surface Boiling of Liquids," Trans. ASME 74, pp. 979-976, 1952.

Stephan, K. and Abdelsalam, M., 1980 "Heat Transfer Correlations for Natural Convection Boiling," International Journal of Heat and Mass Transfer, 23(1), 73-87. http://dx.doi.org/10.1016/0017-9310(80)90140-4

Thome, J., 2006, Boiling Heat Transfer on External Surfaces, Engineering Data Book III, Wolverine Tube Inc., pp. 9-1 and 9-11. 